\title{
Macroprolactinoma in a young man presenting with erectile dysfunction
}

\author{
Seung-Hun Song' ${ }^{1}$ Jinil Lee ${ }^{2}$, Dong Suk Kim ${ }^{1}$ \\ 'Department of Urology and ${ }^{2}$ Andrology Laboratory, Fertility Center of CHA Gangnam Medical Center, CHA University College of Medicine, Seoul, \\ Korea
}

Hyperprolactinemia due to a pituitary adenoma is a rare cause of erectile dysfunction (ED). The prevalence of clinically apparent prolactinomas is reported to be from 6-10 to 50 per 100,000. A few reports have been published of prolactinoma presenting with ED. Here, we report a rare case of a young man who presented with ED as a chief complaint and who was diagnosed with a huge prolactinoma, and we discuss a related fertility issue.

Keywords: Erectile dysfunction; Fertility; Hyperprolactinemia; Prolactinoma

\section{Introduction}

Prolactinomas account for between $25 \%$ and $30 \%$ of functioning pituitary tumors, and they are the most frequent cause of chronic hyperprolactinemia [1]. Hyperprolactinemia due to a pituitary adenoma is a rare cause of erectile dysfunction (ED) [2]. A prolactinoma is likely to be present if the patient's serum prolactin level is greater than $250 \mathrm{ng} / \mathrm{mL}$, and a level of $500 \mathrm{ng} / \mathrm{mL}$ or greater is suggestive of a macroprolactinoma [1]. The physiological consequence of hyperprolactinemia to a pituitary adenoma is hypogonadotropic hypogonadism caused by suppression of pulsatile gonadotropin-releasing hormone $(\mathrm{GnRH})$. Pituitary adenomas can be classified as microadenomas (diameter $\leq 10 \mathrm{~mm}$ ), macroadenomas (diameter $>10 \mathrm{~mm}$ to

Received: June 17, 2019 · Revised: July 11, 2019 · Accepted: August 9, 2019 Corresponding author: Dong Suk Kim

Department of Urology, Fertility Center of CHA Gangnam Medical Center, CHA University College of Medicine, 566 Nonhyeon-ro, Gangnam-gu, Seoul 06135, Korea

Tel: +82-2-3468-2667 Fax:+82-31-969-0500 E-mail:dskim100@chamc.co.kr

*This work was supported by the National Research Foundation of Korea (NRF) with a grant funded by the Korean government (MSIT) (No. 2018R1C1B5083794).

This is an Open Access article distributed under the terms of the Creative Commons Attribution Non-Commercial License (http://creativecommons.org/licenses/by-nc/4.0/) which permits unrestricted non-commercial use, distribution, and reproduction in any medium, provided the original work is properly cited. $\leq 40 \mathrm{~mm}$ ), or giant adenomas (diameter $>40 \mathrm{~mm}$ ) [3].

Approximately one-third of men with hyperprolactinemia may have a pituitary macroadenoma, and these men often exhibit mass effect symptoms, such as headaches and visual field defects [4]. Hyperprolactinemia is a rare cause of male sexual dysfunction although this dysfunction is reversible and can be controlled by medical treatment. If very large, a pituitary tumor may lead to serious endocrine and visual complications. The most common treatment for pituitary macroadenomas is surgical resection using a transsphenoidal approach, and the most common surgical complications are meningitis, leakage of cerebrospinal fluid from the nose, and hormone deficiencies [5]. In this study, we report a rare case of a young man who presented with ED as his chief complaint. We describe our identification of a macroprolactinoma and discuss the possible effects of macroprolactinoma surgery on fertility.

\section{Case report}

A 32-year-old male patient visited our andrology clinic with a chief complaint of ED. His libido was normal, but he had difficulty attaining and maintaining a rigid erection, and he also reported ejaculatory failure and stated that his symptoms had worsened over the previous 10 years. He was planning to get married and requested an eval- 

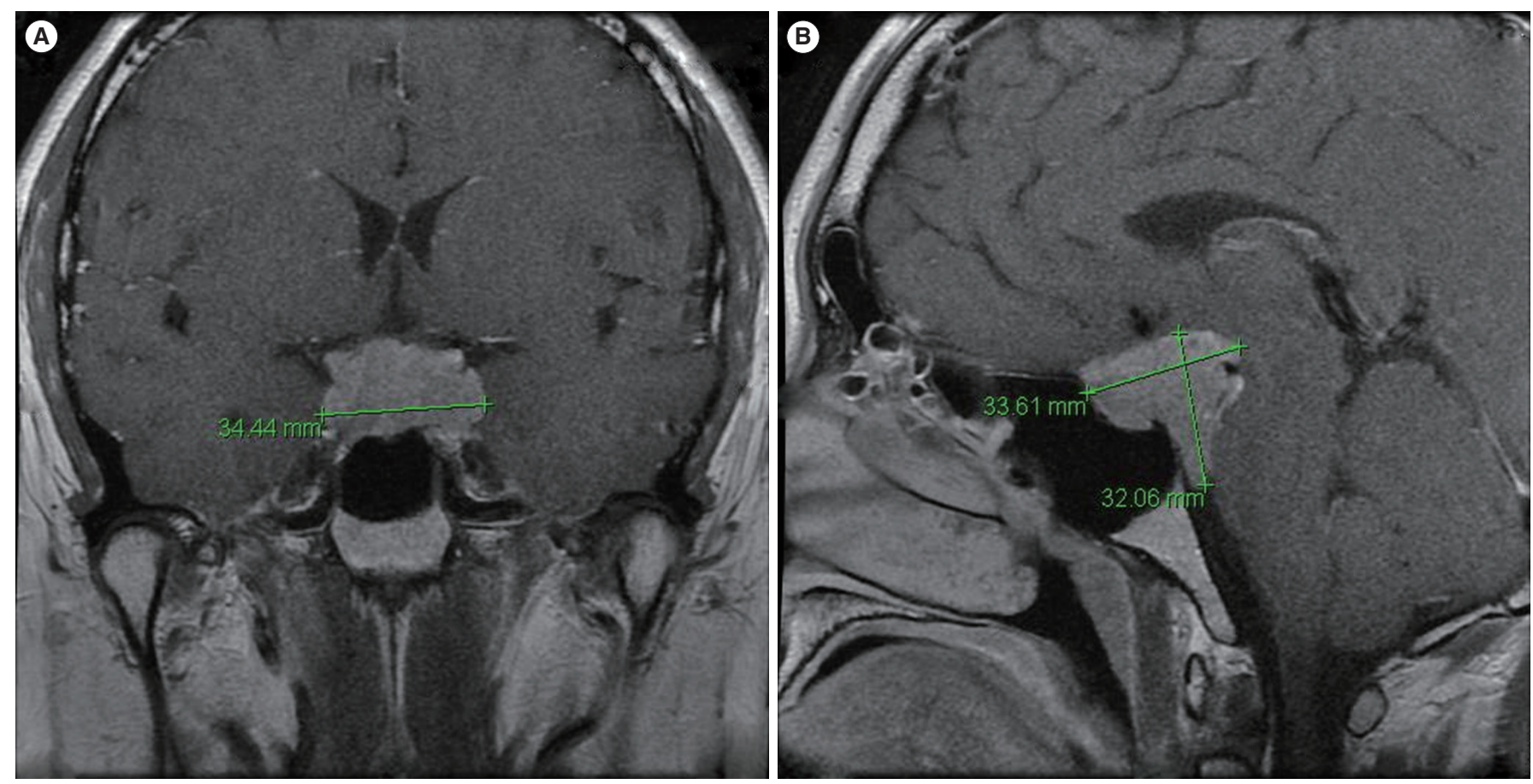

Figure 1. Magnetic resonance imaging of puitary adenoma sized $34.44 \mathrm{~mm} \times 33.61 \mathrm{~mm} \times 32.06 \mathrm{~mm}$ pituitary adenoma. Coronal (A) and sagittal (B) views of the pituitary adenoma.

uation for fertility and impotence. A physical examination indicated that the patient was healthy-looking and had a normal appearance, with a height of $166 \mathrm{~cm}$ and a body mass index of $26.1 \mathrm{~kg} / \mathrm{m}^{2}$. He had a normal male pattern of facial, body, axillary, and pubic hair, and he displayed no gynecomastia. Examination of the external genitalia indicated a normal stretched penile length of $11 \mathrm{~cm}$. The testes were normally positioned in the scrotum, had normal consistency upon palpation, and were normal in size ( $16 \mathrm{~mL}$ each). There were no evident abnormalities of the epididymis or the vas deferens. There was also no evidence of hypertension, diabetes, reduced muscle strength, malformation, neurological symptoms, or visual disturbance. The patient's International Index of Erectile Function-5 (IIEF-5) score was 8, indicating moderate ED. He had normal levels of serum follicle-stimulating hormone ( $2.43 \mathrm{mlU} / \mathrm{mL}$; reference range, $1.5-12.4 \mathrm{mlU} / \mathrm{mL}$ ) and luteinizing hormone $(1.29 \mathrm{mlU} / \mathrm{mL}$; reference range, $1.24-8.62$ $\mathrm{mlU} / \mathrm{mL})$ and low levels of testosterone $(1.14 \mathrm{ng} / \mathrm{mL}$; reference range, $2.49-8.36 \mathrm{ng} / \mathrm{mL}$ ). His serum prolactin level was greatly elevated $(1,008.68 \mathrm{ng} / \mathrm{mL}$; reference range, $4.04-15.2 \mathrm{ng} / \mathrm{mL})$. Semen analysis showed that sperm concentration ( $78 \mathrm{million} / \mathrm{mL})$, total motility (44\%), and strict morphology (4\%) were normal. Based on a diagnosis of hyperprolactinemia, we performed magnetic resonance imaging of the brain. The results indicated the presence of a 34.44 $\mathrm{mm} \times 33.61 \mathrm{~mm} \times 32.06 \mathrm{~mm}$ lobulated and enhancing mass in the sellar and suprasellar area, without involvement of the optic chiasm (Figure 1).
We diagnosed the patient with a pituitary macroadenoma, and an endocrinologist recommended surgical removal using a transsphenoidal approach to control tumor growth and prevent neurological sequelae. Because the patient was planning to get married in the near future, we recommended sperm banking for fertility cryopreservation before surgery. Pathological diagnosis confirmed the presence of a pituitary adenoma. A follow-up appointment 24 months after surgery indicated that the patient's serum prolactin and testosterone had returned to normal levels of $12.8 \mathrm{ng} / \mathrm{mL}$ (normal range, 4.04$15.2 \mathrm{ng} / \mathrm{mL}$ ) and $3.46 \mathrm{ng} / \mathrm{mL}$ (normal range, $2.49-8.36 \mathrm{ng} / \mathrm{mL}$ ), respectively. Additionally, the patient's erectile function had improved, with an IIEF-5 score of 19.

\section{Discussion}

We report the case of a young man who presented with ED as a chief complaint and who was diagnosed with a macroprolactinoma in evaluation of hyperprolactinemia. We recommended sperm banking for fertility preservation before transsphenoidal approach surgery to treat the macroprolactinoma. Endocrine disorders only rarely cause $E D$, and the prevalence of hyperprolactinemia in men with $E D$ ranges from $1 \%$ to $5 \%$ [2]. Buvat [6] reported a low prevalence of marked hyperprolactinemia $(0.76 \%)$ defined as a prolactin level higher than $35 \mathrm{ng} / \mathrm{mL}$ and a low prevalence of pituitary adenoma $(0.4 \%)$ among 3,265 patients who presented with ED. Hyperprolac- 
tinemia can directly influence spermatogenesis and steroidogenesis by acting on prolactin receptors present in Sertoli cells and Leydig cells in the testes [7]. Hyperprolactinemia also induces hypogonadism by interfering with the secretion of GnRH from the hypothalamus [8], which may give rise to ED, decreased libido, and poor semen quality. Studies of semen quality in patients with hyperprolactinemia showed reduced sperm quality, but their results diverged with regard to sperm count, with a mean sperm concentration of 6 million/ $\mathrm{mL}$ [9] in one study and 30 million/ $\mathrm{mL}$ [10] in the other. Our patient exhibited markedly high serum prolactin $(1,008.68 \mathrm{ng} / \mathrm{mL})$ and low serum testosterone $(1.14 \mathrm{ng} / \mathrm{mL})$ levels, and his chief complaint was ED with normal libido and normal sperm quality. The mechanism by which normal sperm quality is maintained in hypogonadal men is not clear; however, despite the low serum testosterone discussed in our report, the combined effect of intratesticular testosterone and follicle-stimulating hormone may be sufficient to induce normal spermatogenesis. Additionally, the duration of the testosterone deficiency may impact sperm quality. However, intratesticular testosterone or the duration of the testosterone deficiency were not assessed in this patient, which is a limitation of this report.

Approximately one-third of men with hyperprolactinemia have pituitary macroadenomas, and these individuals may demonstrate mass effect symptoms, such as headaches and visual field defects [4]. Late diagnosis of a giant pituitary adenoma can lead to permanent neurological complications, such as visual field defects. Men with hyperprolactinemia may present with ED, decreased libido, infertility, gynecomastia, decreased bone mass, and galactorrhea [11]. Thus, the clinician should investigate the possible presence of headaches, galactorrhea, decreased libido, ED, and visual field defects in patients with hyperprolactinemia.

Clinicians may treat a prolactinoma with a dopamine agonist, such as cabergoline or bromocriptine, or with transsphenoidal surgical excision [4]. Most prolactinomas are benign, and microadenomas can be controlled with drug treatment. Pituitary macroadenomas often require surgical resection, and transsphenoidal surgery can achieve normalization of serum prolactin levels in $65 \%$ to $85 \%$ of patients with microadenomas and $30 \%$ to $40 \%$ of those with macroadenomas [4]. Recent advances in surgical and endoscopic procedures used for the resection of macroprolactinomas have decreased the invasiveness and potential morbidity from surgery; however, surgical removal of a huge pituitary mass may still lead to complications such as meningitis, leaking of cerebrospinal fluid from the nose, and pituitary hormone deficiencies [5]. A study aiming to evaluate the hypothalamic-pituitary axes of 83 patients who underwent transsphenoidal surgery for pituitary adenoma reported that by 3 months postsurgery, one patient had developed hypopituitarism [12]. A retrospective review of 519 patients who underwent pituitary adenoma resection using an endoscopic endonasal approach reported that the incidence of new anterior pituitary insufficiency after 2 months was 3.1\% $(n=16)$ [13]. Loss of a functional pituitary gland due to surgical removal could induce permanent hypogonadotropic hypogonadism, leading to male infertility, including azoospermia. Therefore, hypopituitarism as a potential complication of surgery should be discussed with the patient as part of the decision-making process.

Although endocrine disorders only rarely cause ED, evaluation of the levels of prolactin and other serum hormones may be recommended in otherwise healthy men who present with ED and decreased libido. If the patient is of reproductive age, then sperm banking for fertility preservation should be considered prior to surgical treatment of a pituitary adenoma.

\section{Conflict of interest}

No potential conflict of interest relevant to this article was reported.

\section{ORCID}

$\begin{array}{ll}\text { Seung-Hun Song } & \text { https://orcid.org/0000-0003-4649-9129 } \\ \text { Jinil Lee } & \text { https://orcid.org/0000-0001-5102-3278 } \\ \text { Dong Suk Kim } & \text { https://orcid.org/0000-0001-7350-0303 }\end{array}$

\section{Author contributions}

Conceptualization: SHS. Data curation: JL. Formal analysis: SHS, DSK. Funding acquisition: SHS. Methodology: SHS, DSK. Project administration: SHS. Visualization: SHS. Writing - original draft: SHS, DSK. Writing - review \& editing: SHS, DSK.

\section{References}

1. Majumdar A, Mangal NS. Hyperprolactinemia. J Hum Reprod Sci 2013;6:168-75.

2. Zeitlin SI, Rajfer J. Hyperprolactinemia and erectile dysfunction. Rev Urol 2000;2:39-42.

3. Buchfelder M, Schlaffer S. Imaging of pituitary pathology. Handb Clin Neurol 2014;124:151-66.

4. Gillam MP, Molitch ME, Lombardi G, Colao A. Advances in the treatment of prolactinomas. Endocr Rev 2006;27:485-534.

5. Barker FG 2nd, Klibanski A, Swearingen B. Transsphenoidal surgery for pituitary tumors in the United States, 1996-2000: mortality, morbidity, and the effects of hospital and surgeon volume. J Clin Endocrinol Metab 2003;88:4709-19.

6. Buvat J. Hyperprolactinemia and sexual function in men: a short review. Int J Impot Res 2003;15:373-7. 
7. Masud S, Mehboob F, Bappi MU. Severe hyperprolactinaemia directly depresses the gonadal activity causing infertility. Esculapio J Services Inst Med Sci 2007;2:25-7.

8. Molitch ME. Diagnosis and treatment of pituitary adenomas: a review. JAMA 2017;317:516-24.

9. De Rosa M, Colao A, Di Sarno A, Ferone D, Landi ML, Zarrilli S, et al. Cabergoline treatment rapidly improves gonadal function in hyperprolactinemic males: a comparison with bromocriptine. Eur J Endocrinol 1998;138:286-93.

10. Colao A, Vitale G, Cappabianca P, Briganti F, Ciccarelli A, De Rosa $M$, et al. Outcome of cabergoline treatment in men with prolactinoma: effects of a 24-month treatment on prolactin levels, tu- mor mass, recovery of pituitary function, and semen analysis. J Clin Endocrinol Metab 2004;89:1704-11.

11. Klibanski A. Clinical practice: prolactinomas. N Engl J Med 2010;362:1219-26.

12. Hout WM, Arafah BM, Salazar R, Selman W. Evaluation of the hypothalamic-pituitary-adrenal axis immediately after pituitary adenomectomy: is perioperative steroid therapy necessary? J Clin Endocrinol Metab 1988;66:1208-12.

13. Paluzzi A, Fernandez-Miranda JC, Tonya Stefko S, Challinor S, Snyderman CH, Gardner PA. Endoscopic endonasal approach for pituitary adenomas: a series of 555 patients. Pituitary 2014;17: 307-19. 